Case 10 (19 October 1962); Case 12 (24 February 1964); Case 14 (9 September 1962); and Case 16 (17 February 1963). Case 5 received 10 further courses of melphalan, and the disease remained well controlled until the last 10 weeks of life, when the growth extended extremely rapidly. He received one further course of radiotherapy for local pain. Case 9 received eight further courses of melphalan, and the disease was well controlled except for local pain from pathological fractures of ribs which was relieved by irradiation. At post-mortem examination a gastric carcinoma, suspected in the last three months of life, was found. Cases 8, 9, 12, 14, and 16 did not benefit from melphalan therapy. Seven further patients have been treated, four of whom obtained relief of pain for periods up to 16 months; one did not respond to melphalan or to cyclophosphamide, and required repeated courses of local irradiation; two patients in renal failure failed to respond, and in one case profound and prolonged neutropenia and thrombocytopenia followed each of two courses of melphalan lasting 14 and 7 days at a daily dose of $5 \mathrm{mg}$.

\section{REFBRENCES}

Alwall, N. (1947). Lancet, 2, 388.

Bergel, F., and Stock, J. A. (1953). A.R. Brit. Emp. Cancer Campgn, 31, 6.

Bergsagel, D. E. (1962). Cancer Chemother. Rep., No. 16, p. 261.

Sergsagel, D. E. C. C., Austin, C., and Griffith, K. M. (1962). Ibid., No. 21, p. 87.

Bernard, J., Seligmann, M., and Danon, F. (1962). Nouv. Rev. franç.

Hémat., 2, 611.
Blokhin, N., Larionov, L., Perevodchikova, N., Chebotareva, L., and Merkulova, N. (1958)." Ann. N.Y. Acad. Sci., 68, 1128.

Innes, J. (1963). Proc. roy. Soc. Med., 56, 648.

and Rider, W. D. (1955). Blood, 10, 252.

Larionov, L. F., Khokhlov, A. S., Shkodinskaja, E. N., Vasina, O. S., Troosheikina, V. I., and Novikova, M. A. (1955). Bull. exp. Biol. Med. (N.Y.), 1, 48 .

Loge, J. P., and Rundles, R. W. (1949). Blood, 4, 201.

Loge, J. P., and Rundles, R. E. D. (1951). F. Amer. med. Ass., 147, 824. Matthias, J. Q., Misiewicz, J. J., and Scott, R. B. (1960). Brit. med. F.,

2, 1837. . (1949). Cancer, 2, 475.

Swan, A. (1962). Proceedings of Eighth Congress of European Society of Haematology, p. 162. Karger, Basle.

Videbaek, A. (1962). Proceedings of Ninth Congress of the International Society of Haematology. In press.

Waldenström, J. (1964). Brit. med. f., 1, 859.

\title{
Subcutaneous Phycomycosis : A Review of 31 Cases Seen in Uganda
}

\author{
D. P. BURKITT,* M.D.; F.R.C.S.ED. ; A. M. M. WILSON,* B.A., B.M., B.CH., DIP.BACT. \\ D. B. JELLIFFE, $*$ M.D., F.R.C.P.
}

[With Special Plate]

Brit. med. F., 1964, 1, 1669-1672

Subcutaneous phycomycosis is an infection of the subcutaneous fat by a fungus of the family Entomophthoraceae, usually of the genus Basidiobolus, that results clinically in a slowly increasing painless area of subcutaneous induration which is small initially but can sometimes reach very large dimensions.

The clinical syndrome of subcutaneous phycomycosis was first reported from Indonesia by Lie Kian Joe et al. (1956). Subsequently eight further cases were reported from Indonesia (Lie Kian Joe et al., 1959, 1960, 1962 ; Symmers, 1960 ; Lie Kian Joe and Nio-Injo Tjoei Eng, 1960). Six cases have now been reported from Africa: two of these from Uganda (Jelliffe et al., 1961, 1962), one from Kenya (G. Neville and R. Miller, personal communication, 1962), one from the Cameroons (Blanche et al., 1961), one from the northern Sudan (Lynch and Husband, 1962), and one from Nigeria (Elebute and Okubadejo, 1962).

The description of phycomycosis given here is based on a series of 31 patients seen in Uganda, 21 of whom were examined personally by at least one of us. The others were traced through a retrospective survey of histological sections and hospital case-notes. This series includes the two cases previously reported from Uganda.

The clinical features of this lesion, which have been summarized by Burkitt et al. (1963), are characteristic. The condition had in fact been recognized as a clinical entity at Mulago Hospital for many years before the responsible organism was identified on histological section or growth in culture. The real nature of the lesion was not recognized until 1961, when Beaver identified the responsible organism in tissue removed from a child in Mulage Hospital (Jelliffe et al., 1961). One of

* From the Departments of Surgery, Medical Microbiology, and Paediatrics, Makerere College Medical School and Mulago Hospital, Kampala, Uganda. us (A.M.M.W.) at the same time recognized another case in Kampala as a mycosis and subsequently cultured the organism.

\section{Geographical Distribution}

As has been pointed out, the earliest reports came from Indonesia. The first recognition of the condition in Africa came from Uganda in 1961. Cases have now been observed from all four provinces in Uganda, and it would seem that the condition is widespread in that country (Fig. I). Recently it has also been reported from the northern Sudan, Kenya, and the Cameroons (Fig. II). Although only one case has been reported from Nigeria, some six further cases have been recognized at Ibadan (R. Harman, personal communication, 1962).

One of us (D. P. B.), on a recent visit to Ghana, recognized this lesion in a boy aged 7 years in Accra. A typical lesion involved the buttocks and encircled the anal canal, producing a firm stricture. Tissue removed for section showed the characteristic histological appearances, and the responsible organism was cultured.

It is unlikely that these are sporadic and isolated cases occurring across tropical Africa, and it would seem reasonable to expect that as the condition becomes increasingly recognized it will be found to be very widely distributed. So far there is no evidence of its occurrence in the Rhodesias or South Africa, although workers there have been aware of the features of this lesion.

\section{Clinical Aspects}

Age Incidence.-Seventeen of these patients $(55 \%$ of the total) were under the age of 9 , and only two apart from a record of "adult" were over the age of 20 (Fig. III). The few adult 
cases indicate that this condition is not confined to children as had previously been suggested by Elebute and Okubadejo (1962), who drew attention to the fact that "all the cases described so far have been in children." This is, however, predominantly a disease of early childhood.

Sex Incidence.-The sex ratio in this series showed a male preponderance of three to two. This is probably not an

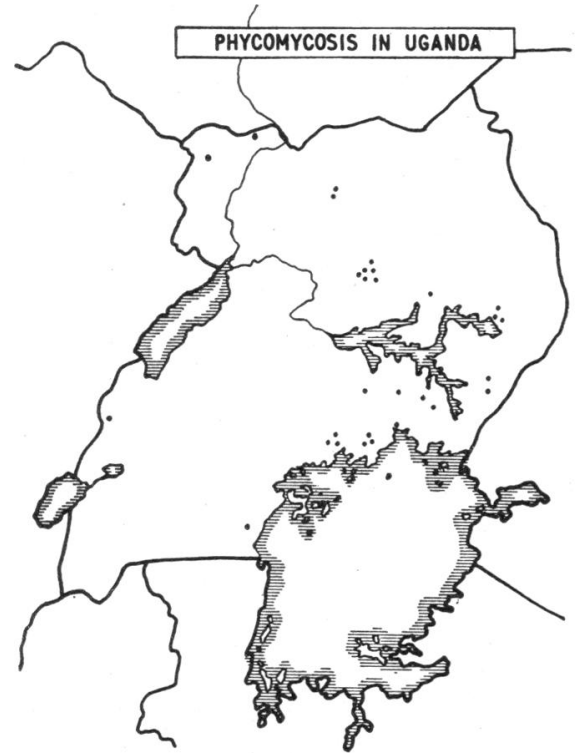

FIG. I.-Map of Uganda showing known distribution of subcutaneous phycomycosis.

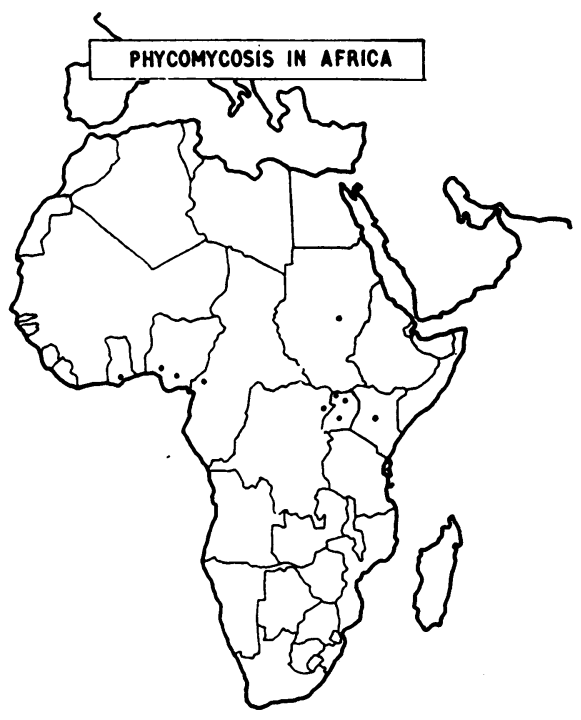

FIG. II.-Map of Africa showing areas in which cases of subcutaneous phycomycosis have been observed.

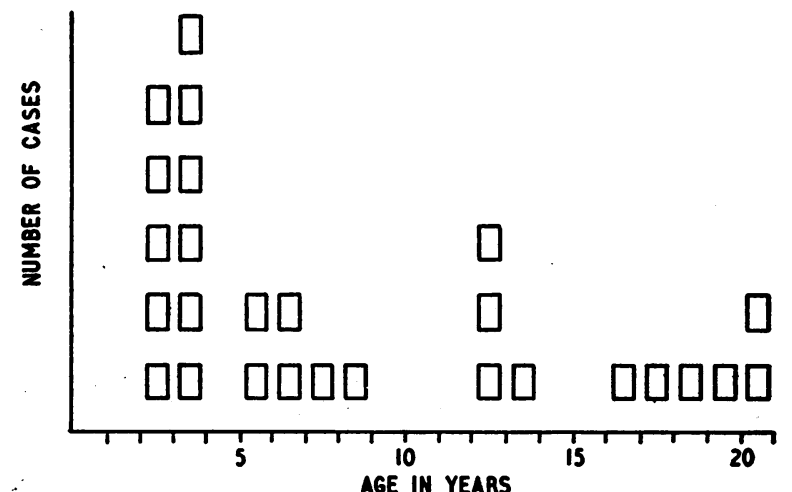

Frg. III.-Age distribution in the 27 Uganda cases in which age has been recorded. In four cases the age was unknown. accurate assessment, seeing that considerably more males than females are admitted to Mulago Hospital.

\section{Clinical Features}

Local Lesion.-The "feel" of the lesion on palpation is strikingly characteristic and gives the impression that a clearly demarcated area of skin and subcutaneous tissue has been coagulated as if by an electric current. This "plaque" of tissue is woody hard and not only can it be moved over the underlying deep structures but by flexing the fingers over the margins of the lesion it can, when relatively small, be virtually lifted off the deeper tissues. Although the margin of the lesion is easily defined, small firm nodules can often be palpated in advance of the growing edge. With the exception of these islands of disease the transition from normal to pathological tissue is sharp. The surface of the lesion is smooth and firm and slightly raised above the surrounding skin. Unlike a

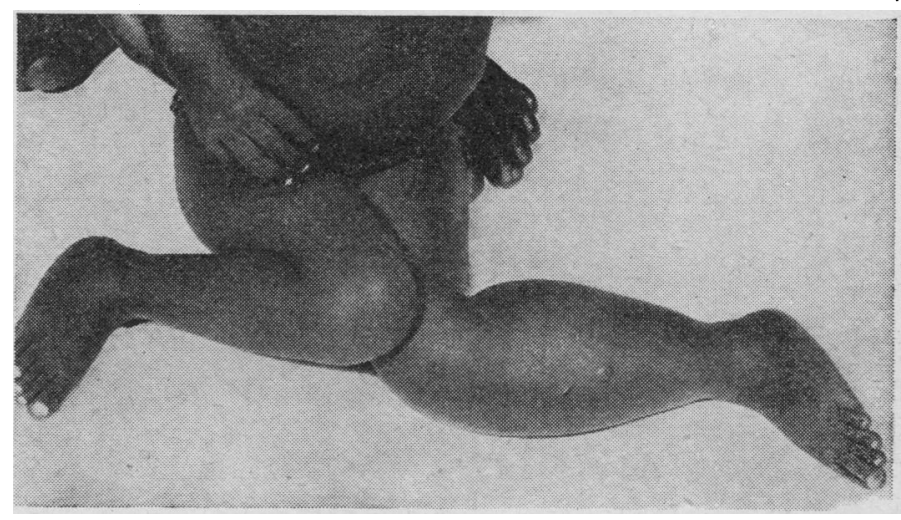

FIG. IV.-Subcutaneous phycomycosis involving the left leg between the knee and the ankle in a girl aged 3 years.

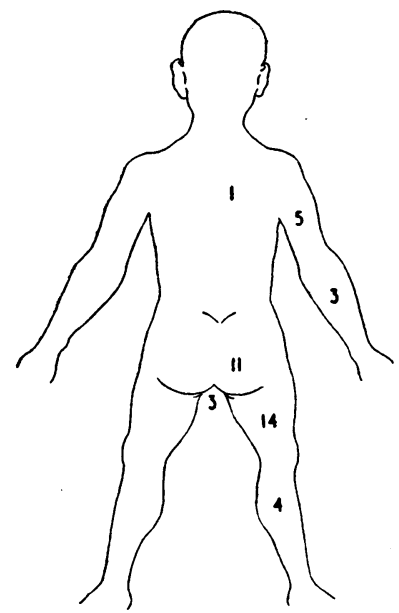

Fig. V.-Distribution of lesions.

These are divided into trunk, upper arm, forearm, buttock, perıneum, thigh, and lower leg.

lymphatic oedema, it does not pit on pressure. The skin overlying the tumour is occasionally more darkly pigmented than the surrounding skin. Although episodes of pain were recorded in some cases, the general absence of pain or tenderness are among the most characteristic features.

Structures Involved.-As the name implies, this is primarily a lesion involving the subcutaneous tissues. The skin, however, is intimately involved. Available evidence suggests that structures beneath the deep fascia are not usually invaded but that penetration into muscle and deeper tissues may occur in advanced cases. 
Regional Lymph Nodes.-Only occasionally were these enlarged, and since gland biopsies were not done, there is no evidence that this was related to the phycomycosis.

Constitutional Disturbance.-This was absent or minimal in all patients observed by us.

Blood Changes.-There was no pronounced evidence of leucocytosis or eosinophilia, although the latter might have been expected in view of the histological findings.

Site of Lesion (Figs. IV and V).-In all but one of the patients the lesions appeared first on the limbs, and in only two did they spread to the trunk. One of these was an upward extension from the arm on to the pectoral region and neck, and the other an extension from the leg on to the pubic region. A lower limb was involved in 18 patients. In addition, buttock lesions were recorded in 11 . The upper limb was involved in only seven patients. The proximal part of the limbs were involved three times more often than the distal half. If buttock lesions are included with leg lesions, the disparity becomes four to one. There would appear to be a particular predilection for the buttocks, which were involved in nine patients, in two of whom both buttocks were involved. In no single instance was involvement of a hand or foot observed.

\section{History}

The lesion appears to start as a small nodule which spreads slowly in all directions. By the time the patient reports to hospital the lesion has usually been present for several months, the average length of history in the 23 cases in which the duration of symptoms was recorded being five and a half months, and varying from two weeks to two years.

It has not been possible to obtain any specific history of trauma relating to the onset of the "lump," and in only a few instances were episodes of pain recorded.

\section{Differential Diagnosis}

Lymphatic Oedema.-This lacks the distinctive "edge" of phycomycosis, and it is characteristic of the latter process that even when a limb is completely encircled with the lesion the hand or foot remains unaffected.

Subcutaneous Malignant Lymphoma.-These lesions are in themselves not unlike early nodules of phycomycosis. They are, however, usually associated with other manifestations of the African lymphoma syndrome and they grow much more rapidly than phycomycosis (Burkitt and O'Conor, 1961 ; Burkitt, 1962).

Induration Round Site of an Injection.-Like phycomycosis, these lesions are often encountered on the buttocks. They are less well defined and are usually both tender and painful. A history of a recent injection may clarify the diagnosis.

\section{Progress Without Treatment}

The lesions progress in the subcutaneous tissues and sometimes completely encircle the affected limb. It may be that at some stage the process terminates spontaneously. Almost total regression was observed in one patient who had received no adequate treatment.

\section{Treatment}

Oral potassium iodide would appear to be an efficient, cheap, and easily administered therapeutic agent. In 1956, when the condition was known only as a clinical and histological entity, Raper commented on the success of this drug. More recently Lie Kian Joe et al. (1962) reported success with it in massive doses.
So far we have treated seven patients with potassium iodide in doses of approximately $30 \mathrm{mg} . / \mathrm{kg}$. of body weight per day for about two weeks. In all of them, with the exception of one adult patient, the lesion had either markedly regressed or virtually disappeared, except for some residual fibrous induration, within three to four weeks. It has been possible to follow up only one of these children longer than two months and he was symptom-free after six months.

\section{Laboratory Aspects}

\section{Morbid Anatomy}

The tissue removed at biopsy shows a fairly consistent picture. The mass is pale and firm. It can be cut with some difficulty and feels fibrous. In the middle of the lesion subcutaneous tissue is intimately bound to the skin, but at the edge the mass is separated from other tissues, both above and below, by congested subcutaneous fat. The outlying nodules, palpable clinically, can sometimes be shown to be peninsulars joined to the main mass by a narrow neck of pale firm tissue. There are no microscopically recognizable collections of pus.

\section{Histology}

The histological picture varies considerably from one part of the lesion to another. At the edge the abnormalities are all in the subcutaneous fat. It is congested and there are loose collections of acute inflammatory cells, both neutrophil and eosinophil, among which fungal hyphae can sometimes be seen. The walls of the hyphae are thin and take up very little haematoxylin, and their cytoplasm is often absent. These hyphae often show up only as circular or oval spaces surrounded by a slightly refractile envelope, unless special fungal stains are used. Further from the edge of the lesion the inflammatory cells form definite micro-abscesses, and the fungus wall may be surrounded by a cuff of finely granular eosinophil material. The fungal hyphae vary very much in diameter (from about 5 to $30 \mu$ ) and show occasional septa and rare branching (Special Plate, Fig. 1).

The pink ring surrounding an apparently empty space is one of the easiest of the characteristic features to see in a section. Its nature has not yet been determined, but it is periodic-acidSchiff (P.A.S.)-positive and very reminiscent of the material which surrounds the organisms in the asteroids of sporotrichosis and in the grains of actinomycosis and the nocardial type of Madura foot (Special Plate, Fig. 2). It may be possible to demonstrate that it contains host antibodies as well as parasite antigens. In this part of the lesion some hyphae lie not in micro-abscesses but surrounded by a palisade of epithelioid cells or enclosed by multinucleate giant cells which appear to be formed by the fusion of the epithelioid cells in the palisade (Special Plate, Fig. 3).

The central part of the lesion is relatively avascular and contains few acute inflammatory cells. Multinucleate giant cells are, however, present and contain fragments of hyphae and/or eosinophilic granular debris. In what appear to be the oldest parts of the lesion there is little but fibrous tissue. It usually extends up into the dermis and here and there contains scattered giant cells, sometimes with but more often without any P.A.S.positive material.

The changes in the picture from the active edge to the older central area suggest the stages of a successful cellular and perhaps humoral reaction on the part of the host to a parasite which can persist in the tissue for some time but is of low virulence and is normally overcome.

The histological reaction has been recognized for some time (Raper, 1956), but the poorly staining walls of the fungal hyphae and their frequent lack of cytoplasm make them diff- 
cult to recognize as such. For many years, therefore, in Uganda these " tunnels" in subcutaneous tissue infiltrated with inflammatory cells, often predominantly eosinophilic, were thought to be the track of an unidentified helminth larva.

From the above description it will be appreciated that neither a biopsy of the skin and the upper part of the subcutaneous tissue over the edge of the lesion nor even a deeper biopsy into the middle of it may show anything but normal tissue or a non-specific inflammatory reaction. Biopsy should therefore be taken near the edge of the lesion and go through the full depth of the subcutaneous tissue. It is perhaps worth mentioning that satisfactory material for histological diagnosis can sometimes be obtained by needle biopsy, a process which, in parts of the world where this condition has been found, is usually much easier to organize than a full surgical biopsy.

\section{Mycology}

In the histological sections there are no characteristics on which a firm diagnosis of the causative fungus can be made; but in our present state of knowledge a fungus in subcutaneous tissue with thin walls and occasional septa provoking an acute inflammatory reaction, including eosinophils and surrounded by cuffs of eosinophilic granular material, is probably a species of Basidiobolus.

In contrast with the majority of fungi pathogenic for man, B. ranarum grows quickly in artificial culture and a presumptive cultural diagnosis may be available as soon as the histological one. Fragments of tissue up to $2 \mathrm{~mm}$. in diameter may be planted on Sabouraud's medium or blood agar and produce characteristic radially folded, matt, wax-coloured colonies 10-15 $\mathrm{mm}$. in diameter in three days.

Hyphae are large and branching, with widely spaced septa. The cytoplasm is often concentrated near the septum and empty segments are common, a feature which may account in part for the rarity with which cytoplasm is seen in the histological sections. The diagnostic zygospores of the genus Basidiobolus are usually recognizable after a week (Special Plate, Fig. 4).

Chopping the tissue in small fragments gives better results than grinding it. Incubation at $37^{\circ} \mathrm{C}$. gives rather larger colonies than at room temperature, and it is worth noting that if tissue is placed in the refrigerator the fungus may die in less than a week.

\section{Discussion}

Although the clinical features of subcutaneous phycomycosis are characteristic and easily recognized, and the responsible organism, Basidiobolus, can be demonstrated on histological section, cultured, and readily identified, the mode of infection or natural history of the disease is still obscure. The superficial nature of the lesion suggests an external inoculation.

Organisms introduced through minor trauma, such as those producing mycetoma, usually produce lesions on the feet, which so far have been totally exempt from phycomycosis. On the other hand, infections introduced through insect-bites are common on the exposed parts of the body, whereas phycomycosis tends to affect the proximal portions of the limbs, which, at least in the lower extremities, are usually covered.
It may, however, be that infection enters the skin when sitting or lying at night, rather than when walking about during the day. The upper arms, buttocks, and thighs are likely to be more firmly approximated to the ground than the forearms, hands, or feet.

It is known that the fungus is widespread in nature. It is a saprophyte in the alimentary canal of insectivorous reptiles, such as lizards, frogs, gekkos, and chameleons, and naturally infected horses have been reported from Indonesia and the U.S.A. (Tio Tiong Hoo et al., 1962). The ground is therefore apt to be contaminated and insects are known to become infected with the fungus from this source.

\section{Summary}

Subcutaneous phycomycosis was first described in Indonesia in 1956. Thirty-one cases have now been recorded in Uganda. It was in this country that the first African case was recognized in 1961. All the fungi isolated have been Basidiobolus species. Since then the condition has been recognized in many countries across tropical Africa, and is believed to be relatively common and widely distributed.

The clinical features of this lesion are strikingly characteristic. These, together with the age incidence and site of distribution on the body, have been described.

The histological appearances and certain aspects of the diagnostic mycology, including biopsy requirements, are discussed. Possible modes of infection are postulated and response to therapy is reviewed.

ADDENDUM.-Since this paper was written four more children have been treated. In two only one buttock was involved, in one a leg and buttock, and in the fourth a leg only.

Grateful acknowledgment is made to the department of medical illustration at Makerere University College Medical School for Figs. I to V, and to Mr. R. Tunnicliffe, of the department of pathology, for Figs. 1, 2, and 3.

\section{REFERENCES}

Blanche, R., Destombes, P., and Nazimoff, O. (1961). Bull. Soc. Path. Burkitt, D. 54, 56. (1962). Postgrad. med. 7., 38, 71. and O'Conor, G. T. (1961). Cancer (Philad.), 14, 258. Wilson, A. M. M., and Jelliffe, D. B. (1963). E. Afr. med. \}., 40 34.

Elebute, E. A., and Okubadejo, O. A. (1962). W. Afr. med. \}., 11, 217. Jelliffe, D. B., Burkitt, D., O'Conor, G. T., and Beaver, P. C. (1961) F. Pediat., 59, 124

-Wilson, A. M. M., and Burkitt, D. (1962). Ibid., 61, 448

Lie Kian Joe and Njo-Injo Tjoei Eng (1960). Ann. N.Y. Acad. Sci. 89, 4.

Pohan, A., Meulen, H. van der, and Emmons, C. W. (1956). Arch. Derm. Syph. (Chic.), 74, 378.

- Sutomo Tjokronegoro, Schaafma, S., and Emmons, C. W. (1959). Amer. F. clin. Path., 32, 62. 9, 143. Topo Harsono, Rukmono, and Njo-Injo Tjoei Eng (1962). F. trop. Med. Hyg., 65, 38.

Lynch, J. B., and Husband, A. D. (1962). F. clin. Path., 15, 126 Raper, A. B. (1956). E. Afr. med. Ұ., 33, 365.

Symmers, W. St. C. (1960). Brit. med. F., 1, 1331.

Tio Tiong Hoo, Njo-Injo Tjoei Eng, and Lie Kian Joe (1962). Derm. trop., 1, 23. 


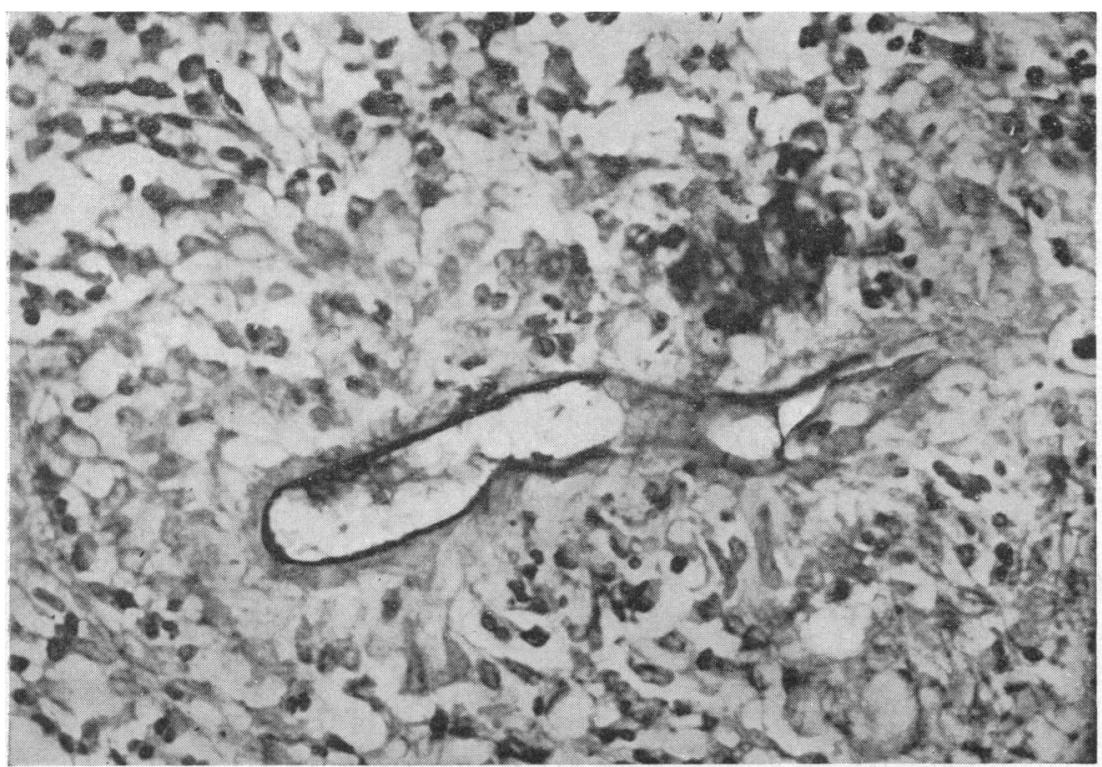

Fig. 1.-Longitudinal section of hypha with one transverse septum. (P.A.S. $\times 430$.)

FIG. 2.-Longitudinal section of hypha with surrounding P.A.S.-positive material. Polymorph and eosinophil reaction present
side amorphous material. (P.A.S. $\quad \times 215$.)

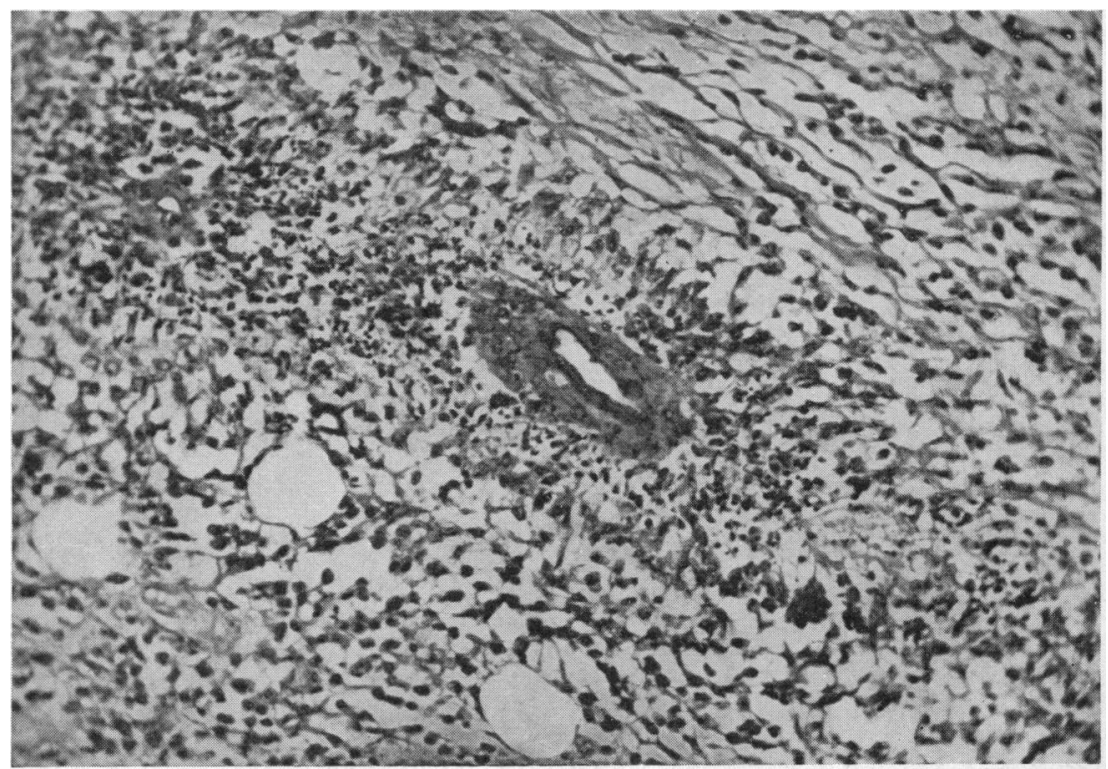

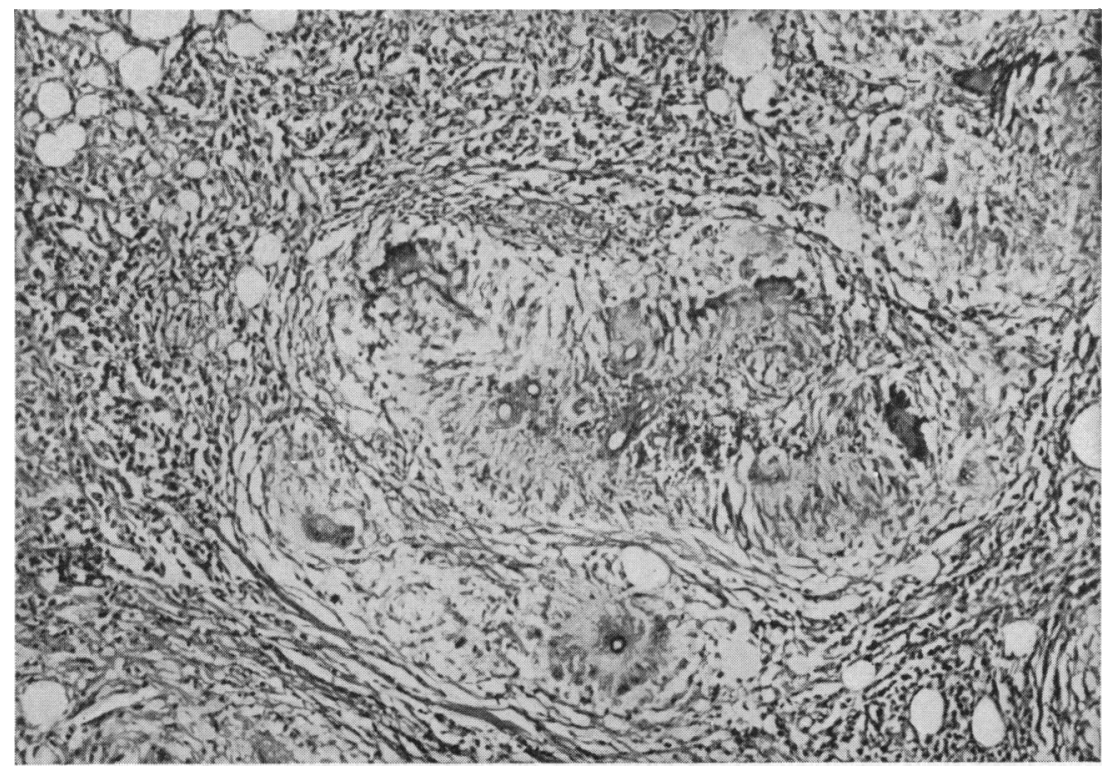

FIG. 3.-Giant-cell and epithelioid-cell reaction around hyphae. Most of these are cut in cross-section. (P.A.S. $\times 95$.)

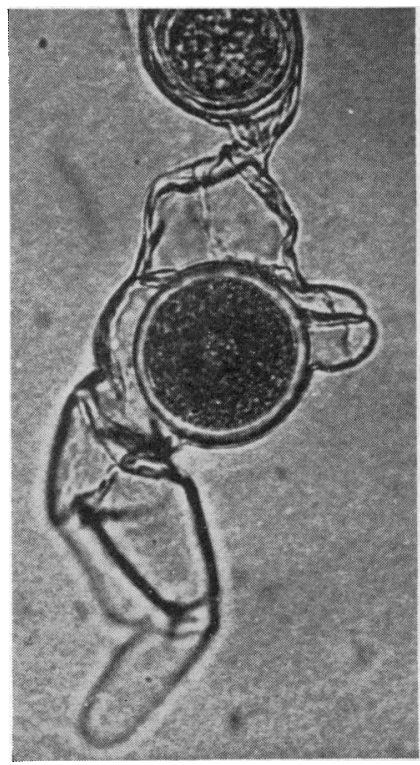

FIG. 4.-Diagnostic zygospore of B. ranarum. 